\title{
Timing and cause of perinatal mortality for small-for-gestational-age babies in South Africa: critical periods and challenges with detection
}

\author{
Tina Lavin ${ }^{1 *}$, David B. Preen ${ }^{1}$ and Robert Pattinson ${ }^{2}$
}

\begin{abstract}
Background: Little information exists on timing and cause of death for small-for-gestational-age (SGA) babies in low-and-middle-income-countries (LMICs), despite evidence from high-income countries suggesting critical periods for SGA babies. This study explored the timing and cause of stillbirth and early neonatal mortality (END, $<7$ days) by small-for-gestational age in three provinces in South Africa. In South Africa, the largest category of perinatal deaths is unexplained stillbirth, of which up to one-quarter have intra-uterine growth restriction.
\end{abstract}

Methods: Secondary analysis of the South African Perinatal Problems Identification Program (PPIP) database allowed for the analysis of gestational age at death and clinically confirmed diagnosis of stillbirth and early neonatal death (END) (>1000 $\mathrm{g}$ and $>28$ weeks) across gestation. Comparisons by province, size-for-gestational-age, gestational age groups, and maternal condition at death were performed. The provinces investigated were: Western Cape (fortnightly antenatal care visits from 32 to 38 weeks), Limpopo and Mpumalanga (no antenatal care visits between 32 to 38 weeks).

Results: There were 528,727 births in the study period and 8111 stillbirths and 5792 early neonatal deaths. Similar timing of deaths across gestation was seen for the three provinces with the greatest proportion of deaths for SGA babies at 33-37 weeks (stillbirths $52.9 \%$; END $43.3 \%$; $p<0.05$ ). SGA babies had a greater proportion of deaths due to hypertension (SGA22.9\%; AGA $18.6 \%$; LGA $18.6 \%$; $p<0.05$ ) and intrauterine growth restriction (SGA $6.8 \%$; AGA $1.7 \%$; LGA $1.4 \%$; $p<0.05$ ). No increase was seen in poor maternal condition for SGA babies and $54.9 \%$ of deaths had a healthy mother. Of mothers that were healthy the greatest proportion of SGA stillbirths were due to unexplained intrauterine death (53.9\%).

Conclusion: There was a peak in stillbirths for SGA babies 33-37 weeks in all provinces. Detecting SGA is further complicated as in most cases the mother is healthy. Further research into Umbiflow Doppler velocimetry use in low-risk populations is warranted and may be a viable strategy to increase current detection of SGA babies at risk of mortality in LMICS.

Keywords: Small-for-gestational-age, Intrauterine growth restriction, Perinatal mortality, South Africa, Low-and-middle-income countries, Doppler

\footnotetext{
* Correspondence: tina.lavin@uwa.edu.au

${ }^{1}$ Centre for Health Services Research, School of Population Health, The University of Western Australia (M431), 35 Stirling Highway, Crawley, WA 6009, Australia

Full list of author information is available at the end of the article
} 


\section{Background}

Approximately $25 \%$ of children born in low-and-middleincome countries (LMICs) are small-for-gestational-age (SGA) [1]. Babies who are SGA are at increased risk of mortality and neonatal morbidity [2, 3], making the detection and clinical management of such infants crucial. The condition may constitute a small but healthy fetus or be due to pathological growth failure (intrauterine growth restriction (IUGR)) [4]. The purpose of identifying SGA fetuses, defined as a birth weight in the lowest decile on standard growth curves [5], is to recognise those most at risk of poor outcomes [3].

Studies to date have indicated that there may be a critical period for increased mortality for SGA babies $[3,5,6]$. A UK study found that stillbirths between 28 and 36 weeks were increased for SGA babies [5]. Other studies have found that SGA babies are at increased risk of stillbirth compared to non-SGA babies at all gestational ages [3], and that the risk of stillbirth for SGA babies increases with advancing gestational age [6].

In South Africa, the largest category of perinatal deaths is unexplained stillbirth, of which up to one-quarter have IUGR [7]. Early recognition can prevent some of these deaths. Early antenatal detection of SGA babies remains a challenge in LMICs, but is important as most deaths occur in the late preterm or term period, where survival of live born infants in well-resourced units is high [8]. As detection of SGA at the population level is challenging due to resource constraints, identifying critical periods and causes of mortality across gestation may elucidate the best approach.

This study explores the gestational age at death and cause of stillbirth and early neonatal mortality (up to 7 days neonatal life) by size-for-gestational age in three South African provinces.

\section{Methods}

Secondary analysis of the South African Perinatal Problems Identification Program (PPIP) database allowed for the analysis of gestational age at death and clinically confirmed diagnosis of stillbirth and early neonatal death (END) across gestation. The program also allowed for comparisons between SGA, appropriate-for-gestationalage (AGA) and large-for-gestational-age (LGA) babies from 1 October and 2013 and 31 August 2015 and between three provinces: Western Cape, Limpopo and Mpumalanga. Western Cape has fortnightly antenatal care visits between 32 and 38 weeks, while Limpopo and Mpumalanga do not have visits between 32 and 38 weeks, preventing the opportunity for detection of SGA at these gestations. These provinces were chosen (from nine available) as they have the greatest PPIP coverage, auditing $>90 \%$ of perinatal deaths. PPIP is a perinatal quality audit system that has been described in detail elsewhere [7, 9]. Briefly, at each clinical site $(n=292)$ across the three provinces the clinical team perform a review shortly after a death has occurred. The primary obstetric cause of death was defined by the PPIP technical team as the main obstetric event or pregnancy occurrence which was integral in the pathway to perinatal death, as described in other published studies [7]. IUGR was also identified at the time of death through clinical evaluation. Maternal condition at the time of death was also recorded. Categories for the primary obstetric cause of stillbirth and early neonatal death were as follows: antepartum haemorrhage, spontaneous preterm labour (intrapartum stillbirth), unexplained intrauterine death, fetal abnormality, hypertensive disorders, infections, intrapartum asphyxia, intrauterine growth restriction, maternal disease, miscellaneous (rhesus isoimmunisation, twin-to-twin transfusion, extra-uterine pregnancy and other cause of death not described), no obstetric cause and trauma. The maternal condition is defined as either healthy (where the clinician examining her could not find any clinical problems) or the occurrence of a recognised medical or obstetric complication (eg. cardiac, endocrine, respiratory disease or other disease that are an indirect cause of morbidity), categorised as coincidental conditions, medical and surgical disorders, non-pregnancy related infections, extra-uterine pregnancy, pregnancy-related sepsis, obstetric haemorrhage, hypertension, anaesthetic complications, embolism, and acute collapse (cause unknown).

Gestational age was calculated based on date of last menstrual period, ultrasound or clinical examination and cases were excluded if the gestation age was unknown or if the estimated age was considered 'uncertain'. There was no hierarchy employed based on method of gestational age estimation. Detailed data were extracted on all stillbirths $>1000 \mathrm{~g}$ and 28-42 weeks gestation and early neonatal deaths less than 7 days of neonatal life. Data were only included up to 42 weeks gestation as Theron weight distribution curves are not considered reliable for growth measurements after 42 weeks gestation $[10,11]$. Only women who had reported receiving antenatal care were included as SGA can be detected antenatally. Data extracted from the three provinces represent $58.6 \%$ of all deaths in South Africa that met the study criteria. Birth weight for gestation was obtained from Theron charts. SGA was defined as neonates with $<10$ th centile for gestational age based on South African specific growth charts $[10,11]$.

\section{Statistical analysis}

Stillbirth and early neonatal death cumulative incidence were calculated for each province using the number of reported births (all births for stillbirth, live births for neonatal death rate) as the denominator. The 
frequencies of deaths occurring across gestation were compared between SGA, AGA and LGA babies as well as between provinces. Comparisons between the proportion of primary cause of deaths were made by size-for-gestational-age, gestational age at death and in relation to maternal conditions. Gestational age was grouped into three categories for analysis: 28-32 weeks, 33-37 weeks and 38-42 weeks. Frequency distributions were performed and Pearson's chi-squared test or Fisher's exact test (where $n<5$ ) were used to determine crude differences between proportions for the key comparisons made (i.e. size-for-gestational-age, gestational age at death, maternal condition and between provinces). Independent $\mathrm{t}$-tests were used to compare means between key groups. A $p$-value $<0.05$ was accepted as statically significant.

The PPIP program has ethical approval from the Faculty of Heath Sciences Ethics Committee at the University of Pretoria. The data are collected with permission from the South African Department of Health. This secondary analysis was approved by the PPIP technical task team and UWA Human Ethics Committee.

\section{Results}

There were 528,727 births $>1000 \mathrm{~g}$ in the study period (Mpumalanga $=145,362$; Western Cape $=173,597$; Limpopo $=209,768)$, of which $8111(1.5 \%)$ were stillbirths (Mpumalanga $=2501 ;$ Limpopo $=3808 ;$ Western Cape $=$ $1802)$ and $3792(0.7 \%)$ died in the early neonatal period $(<7$ days) (Mpumalanga $=1163$; Limpopo $=2124$; Western Cape $=505)$. The cumulative incidence of stillbirth for the study period was highest in Limpopo (18.2 per 1000 births) and Mpumalanga (17.2/1000) compared to Western Cape (10.4/1000). The cumulative incidence of early neonatal death was highest in Limpopo at 10.3 per 1000 live births, followed by Mpumalanga (8.1 per 1000) and Western Cape (3.0 per 1000). After exclusion of deaths prior to 28 weeks (and after 42 weeks), deaths with unknown or uncertain gestation and women who had not received ANC, the number of deaths used for analysis was 6133 (Mpumalanga $n=2198$; Limpopo $n=3032$; Western Cape $n=903)$. The greatest proportion of babies in the study were AGA (61.5\%), followed by SGA (22.6 \%) and LGA (12.3 \%).

\section{Gestational age at death}

There were no differences between provinces in terms of representation and timing of stillbirths between SGA, AGA, LGA, therefore data from the three provinces were combined and presented as means and standard errors. Stillbirths who were AGA or LGA occurred across gestation without any significant increases or decreases. A larger proportion of SBs occurred for SGA babies in the 33-37 week period in all provinces (Fig. 1). When considering macerated and fresh stillbirths a peak at 33-37 weeks was also seen for SGA babies (Fig. 1). A similar pattern was seen for early neonatal deaths (END) with a peak at 33-37 weeks for SGA babies. The timing of END for AGA and LGA babies increased during the 38-42 week period but remained low at $28-32 \mathrm{w}$ and $33-37 \mathrm{w}$.

\section{Primary causes of death \\ Stillbirths by size-for-gestational-age}

The primary cause of stillbirth across the sample was unexplained intrauterine death (33.1\%), followed by intrapartum asphyxia (17.2\%) and hypertensive disorders (19.7\%) (Table 1). Some primary causes of death were more frequent in the SGA group, such as fetal abnormality $(37.8 \%)$ and intrauterine growth restriction (59.8\%) which represented up to half of all deaths despite only representing $26.2 \%$ of the total sample $(p<0.05)$. Intrapartum asphyxia for SGA babies was indicated in $13.3 \%$ of deaths due to intrapartum asphyxia across gestation $(p<0.05)$.

\section{Early neonatal deaths by size-for-gestational-age}

The primary cause of early neonatal death ( $<7$ days) was intrapartum asphyxia (42.1\%), followed by spontaneous preterm labour (18.7\%), fetal abnormality (11.4\%) and hypertensive disorders (7.3\%) (Table 2). Cause of death in SGA babies were intrauterine growth restriction (91.3\%), hypertensive disorders (37.0\%), fetal abnormality $(33.3 \%)$, and spontaneous preterm labour (36.0\%) which represented a large proportion of all deaths by cause despite representing only $23.7 \%$ of the sample.

Stillbirths across gestational age groups (28-32, 33-37, and 38-42 weeks)

The main causes of stillbirth at 28-32 weeks and 33-37 weeks for babies of all gestations were unexplained intrauterine death (34.5\%; $33.4 \%$, respectively), hypertensive disorders (27.7\%; $20.2 \%)$ and antepartum haemorrhage $(18.2 \% ; 17.9 \%)$. For stillbirths during the 38-42 week period the main causes were unexplained intrauterine death (33\%), intrapartum asphyxia (31.1\%) and hypertensive disorders (13.5\%) (Table 3). Mortality was highest in the 33-37 week period with death due to unexplained intrauterine death (31.5\%), hypertension (25.5\%), antepartum haemorrhage (17.0\%). Most deaths for SGA babies from spontaneous preterm labour (70.4\%), antepartum haemorrhage $(64.8 \%)$ and hypertensive disorders $(57.8 \%)$ occurred during the 33-37 week period $(p<0.05)$. Most SGA deaths from intrapartum asphyxia occurred during the 38-42 week period $(p<0.05)$. 


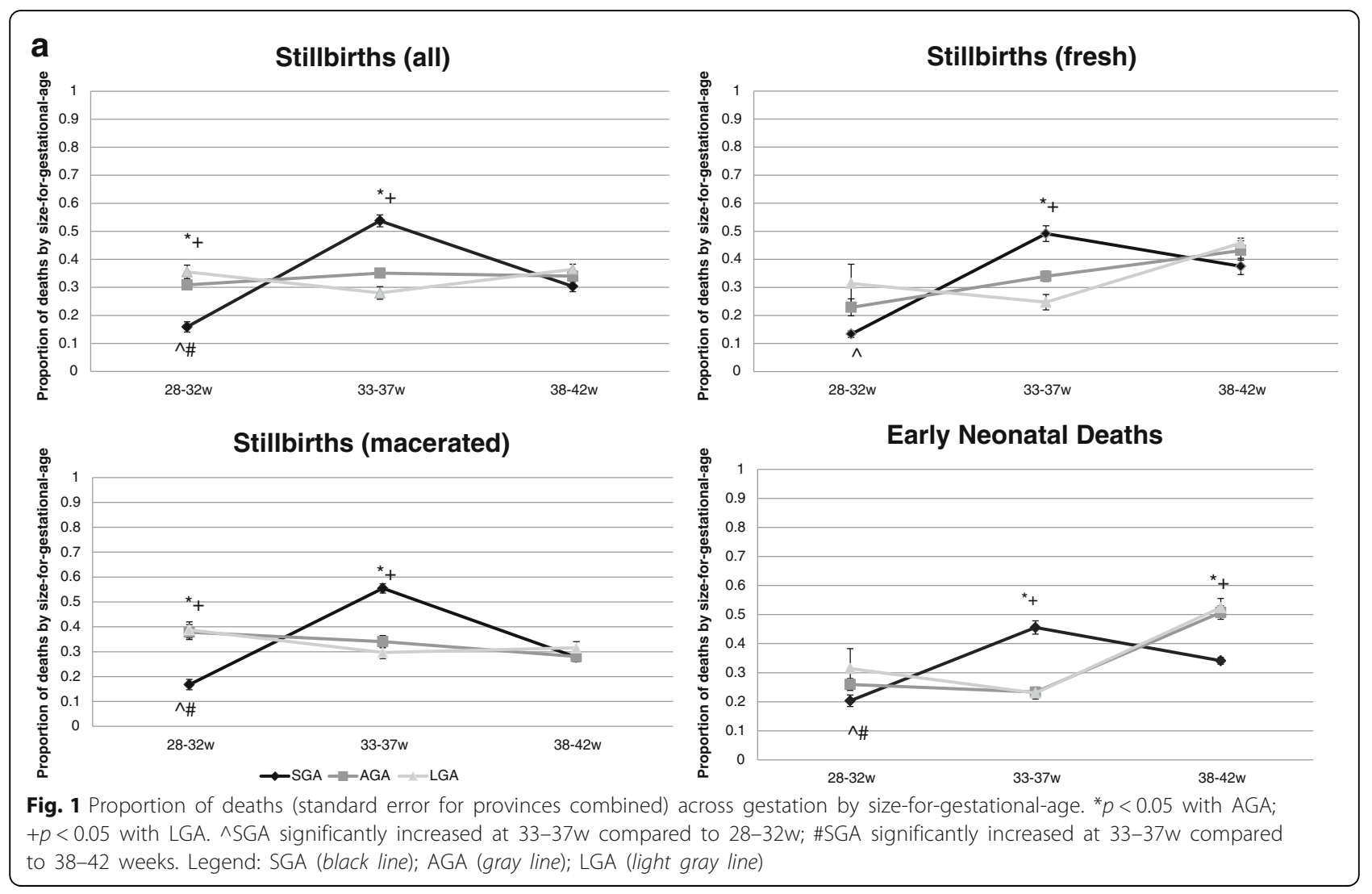

Table 1 Primary cause of stillbirth by size-for-gestation

(Western Cape, Limpopo and Mpumalanga combined); $n=4059$

\begin{tabular}{|c|c|c|c|c|}
\hline \multirow{2}{*}{$\begin{array}{l}\text { Primary cause } \\
\text { of stillbirth }\end{array}$} & \multirow{2}{*}{$\begin{array}{l}\text { SGA } \\
n(\%)\end{array}$} & \multirow{2}{*}{$\begin{array}{l}\text { AGA } \\
n(\%)\end{array}$} & \multicolumn{2}{|l|}{ LGA } \\
\hline & & & $n(\%)$ & All \% \\
\hline $\mathrm{APH}$ & 145 (13.6) & $399(16.0)$ & $51(10.2)$ & 14.7 \\
\hline $\begin{array}{l}\text { Unexplained Intrauterine } \\
\text { death }\end{array}$ & $367(34.5)$ & $812(32.5)$ & $164(32.8)$ & 33.1 \\
\hline Fetal abnormality & $54(5.1)^{*}$ & $67(2.7)$ & $22(4.4)$ & 3.5 \\
\hline Hypertensive disorders & $244(22.9)^{* \wedge}$ & 463 (18.6) & 93 (18.6) & 19.7 \\
\hline Infections & $26(2.4)$ & $42(1.7)$ & $7(1.4)$ & 1.8 \\
\hline Intrapartum asphyxia & $93(8.7)^{*} \wedge$ & $512(20.5)$ & 93 (18.6) & 17.2 \\
\hline $\begin{array}{l}\text { Intrauterine growth } \\
\text { restriction }\end{array}$ & $73(6.8)^{*} \wedge$ & $42(1.7)$ & $7(1.4)$ & 3.0 \\
\hline Maternal disease & $12(1.1)^{*} \wedge$ & $56(2.2)$ & $41(8.2)$ & 2.7 \\
\hline Misc. & $22(2.1)$ & $27(1.1)$ & $6(1.2)$ & 1.4 \\
\hline No obstetric cause & $1(0.1)$ & $2(0.1)$ & $1(0.2)$ & 0.1 \\
\hline Spont. Preterm labour & $27(2.5)$ & $65(2.6)$ & $12(2.4)$ & 2.6 \\
\hline Trauma & $1(0.1)$ & $8(0.3)$ & $2(0.4)$ & 0.3 \\
\hline All & 1065 & 2495 & 499 & 100.0 \\
\hline
\end{tabular}

Table 2 Primary cause of early neonatal death ( $<7$ days) by size-for-gestational age (provinces combined); $n=1742$

Primary cause death SGA AGA LGA
(END)

\begin{tabular}{lcccr} 
& $n(\%)$ & $n(\%)$ & $n(\%)$ & All \% \\
\hline APH & $18(44)$ & $59(5.1)$ & $3(1.6)$ & 4.6 \\
Unexplained Intrauterine & $1(0.2)$ & $2(0.2)$ & $0(0.0)$ & 0.2 \\
death & & & & \\
Fetal abnormality & $66(16.0)^{*}$ & $112(9.8)$ & $20(10.9)$ & 11.4 \\
Hypertensive disorders & $47(11.4)^{*}$ & $68(5.9)$ & $12(6.5)$ & 7.3 \\
Infections & $11(2.7)$ & $26(2.3)$ & $5(2.7)$ & 2.4 \\
Intrapartum asphyxia & $103(25.0)^{* \wedge}$ & $619(54.0)$ & $11(62.0)$ & 42.1 \\
Intrauterine growth & $21(5.1)^{* \wedge}$ & $2(0.2)$ & $0(0.0)$ & 1.3 \\
restriction & $1(0.2)$ & $7(0.6)$ & $2(1.1)$ & 0.6 \\
Maternal disease & $7(1.7)$ & $17(1.5)$ & $5(2.7)$ & 1.7 \\
Misc. & $20(4.9)$ & $44(3.8)$ & $5(2.7)$ & 4.0 \\
No obstetric cause & $117(28.4)^{* \wedge}$ & $190(16.6)$ & $18(9.8)$ & 18.7 \\
Spont. Preterm labour & $0(0.0)$ & $0(0.0)$ & $0(0.0)$ & 0.0 \\
Trauma & 412 & 1146 & 184 & 100.0 \\
All & & &
\end{tabular}


Table 3 Primary cause of stillbirth for SGA babies across GA; $n=1042$

\begin{tabular}{|c|c|c|c|c|}
\hline Primary cause death & $\begin{array}{l}28-32 w \\
n(\%)\end{array}$ & $\begin{array}{l}33-37 w \\
n(\%)\end{array}$ & $\begin{array}{l}38-42 w \\
n(\%)\end{array}$ & $\begin{array}{l}\text { All } \\
n(\%)\end{array}$ \\
\hline $\mathrm{APH}$ & $23(13.5)$ & $94(17.0)$ & $28(8.8)$ & $145(13.9)$ \\
\hline $\begin{array}{l}\text { Unexplained } \\
\text { Intrauterine death }\end{array}$ & $63(37.1)$ & $174(31.5)^{\wedge}$ & $130(40.6)$ & $367(35.2)$ \\
\hline Fetal abnormality & $9(5.3)$ & $30(5.4)$ & $15(4.7)$ & $54(5.2)$ \\
\hline $\begin{array}{l}\text { Hypertensive } \\
\text { disorders }\end{array}$ & $52(30.6)$ & $141(25.5)^{\wedge}$ & $51(15.9)$ & $244(23.4)$ \\
\hline Infections & $3(1.8)$ & $9(1.6)^{\wedge}$ & $14(4.4)$ & $26(2.5)$ \\
\hline Intrapartum asphyxia & $7(4.1)$ & $36(6.5)^{\wedge}$ & $50(15.6)$ & $93(8.9)$ \\
\hline $\begin{array}{l}\text { Intrauterine growth } \\
\text { restriction }\end{array}$ & $7(4.1)$ & $42(7.6)$ & $24(7.5)$ & $73(7)$ \\
\hline Maternal disease & $1(0.6)$ & $6(1.1)$ & $5(1.6)$ & $12(1.2)$ \\
\hline $\begin{array}{l}\text { Spont. Preterm } \\
\text { labour }\end{array}$ & $5(2.9)$ & $19(3.4)^{\wedge}$ & $3(0.9)$ & $27(2.6)$ \\
\hline Trauma & $0(0.0)$ & $1(0.2)$ & $0(0)$ & $1(0.1)$ \\
\hline All & $170(100.0)$ & $552(100.0)$ & $320(100.0)$ & $1042(100.0)$ \\
\hline
\end{tabular}

$\wedge$ with 38-42 week age group; Pearson chi-sq tests, Fisher's exact where cell count $<5$

\section{Early neonatal deaths across gestational age groups (28-32, 33-37, and 38-42 weeks)}

The main causes of early neonatal death at 28-32 weeks were spontaneous preterm labour (57.4\%), hypertensive disorders (14.8\%) and antepartum haemorrhage (10.2\%). For deaths between 33 and 37 weeks the main causes of death were intrapartum asphyxia (47.3\%), fetal abnormality $(17.7 \%)$, spontaneous preterm labour (16 \%) and hypertensive disorders (9.2\%). At 38-42 weeks intrapartum asphyxia was the main cause of death (77.1 \%), followed by fetal abnormality (11.5 \%) (Table 4). The largest causes of death during the 33-37 week period, when SGA deaths peaked, were for spontaneous preterm labour (36.5 \%), fetal abnormality (18.6\%) and intrapartum asphyxia (18.6\%) (Table 4). Most deaths from intrapartum asphyxia for SGA babies occurred during the 38-42 week period (68 \%), while most deaths from hypertensive disorders $(48.9 \%)$ and fetal abnormality (47 \%) occurred during the 33-37 week period $(p<0.05)$.

\section{Maternal condition}

There were no significant differences in the proportion of deaths to healthy mothers by size-for-gestational-age (SGA $n=605,54.9 \%$; AGA $n=1394,55.4 \%$; LGA $n=$ $279,53.8 \%)$. Of mothers who were healthy, the greatest proportion of stillbirths was seen for unexplained intrauterine death (all sizes-for-gestation $50.6 \%$; SGA $53.9 \%$ ). More mothers of SGA babies were hypertensive compared to AGA and LGA babies (SGA $26.3 \%$; AGA $21.6 \%$;
Table 4 Primary cause of ENND for SGA babies at each gestation, $n=385$

\begin{tabular}{lcccr}
\hline Primary cause death & $\begin{array}{c}28-32 \mathrm{w} \\
n(\%)\end{array}$ & $\begin{array}{l}33-37 \mathrm{w} \\
n(\%)\end{array}$ & $\begin{array}{l}38-42 \mathrm{w} \\
n(\%)\end{array}$ & \multicolumn{1}{l}{$\begin{array}{l}\text { All } \\
n(\%)\end{array}$} \\
\hline APH & $8(9.2)$ & $5(3.0)$ & $5(3.5)$ & $18(1.1)$ \\
Unexplained & $0(0.0)$ & $1(0.6)$ & $0(0.0)$ & $1(0.1)$ \\
Intrauterine death & & & & \\
Fetal abnormality & $7(8.0)$ & $31(18.6)^{*}$ & $28(21.4)$ & $66(4.0)$ \\
Hypertensive & $17(19.5)$ & $23(13.8) \wedge$ & $7(5.3)$ & $47(2.9)$ \\
disorders & & & & \\
Infections & $1(1.1)$ & $5(3.0)$ & $5(3.8)$ & $11(0.7)$ \\
Intrapartum asphyxia & $2(2.3)$ & $31(18.6)^{*} \wedge$ & $70(53.4)$ & $103(6.3)$ \\
Intrauterine growth & $2(2.3)$ & $10(6.0)$ & $9(6.9)$ & $21(1.3)$ \\
restriction & & & & \\
Maternal disease & $1(1.1)$ & $0(0.0)$ & $0(0.0)$ & $1(0.1)$ \\
Spont. Preterm labour & $49(56.3)$ & $61(36.5)^{*} \wedge$ & $7(5.3)$ & $117(7.1)$ \\
Trauma & $0(0.0)$ & $0(0)$ & $0(0)$ & $0(0.0)$ \\
All & $87(100.0)$ & $167(100.0)$ & $131(100.0)$ & $385(100.0)$ \\
\hline
\end{tabular}

${ }^{*} p<0.05$ with $28-32 \mathrm{w}$ age group; $\wedge$ with 38-42 week age group; Pearson chi-sq tests, Fisher's exact where cell count $<5$

LGA $21.2 \%$; $p<0.05)$, however fewer mothers of SGA babies had medical and surgical complications compared to LGA babies (SGA $5.1 \%$; LGA $11 \%$; $p$ 0.05).

Causes of stillbirth and condition of mother for SGA babies across gestational groups are presented in Table 5 . Causes of early neonatal death and condition of mother for small-for-gestational age babies across gestational groups are presented in Table 6.

\section{Discussion}

Our findings indicate that there are specific characteristics unique to SGA babies in terms of gestational age at death and causes of perinatal morality.

\section{Timing of perinatal deaths across gestation}

The same pattern of timing of stillbirth across gestation was seen for the three provinces with the greatest proportion of deaths for SGA babies during the 33-37 week period. This was in contrast to AGA and LGA babies where no peaks in the proportion of stillbirths across gestation were seen. This is consistent with observations in high-income countries where peaks have been observed between 34-37 weeks and 32-36 weeks [3, 5]. In the current study a greater proportion of ENDs for SGA babies also occurred during the 33-37 week period, suggesting that this is a critical time for both antepartum and postpartum mortality. It is also well-established that there is increased neonatal mortality for SGA preterm babies compared to AGA preterm babies [1], stressing the vulnerability of SGA babies in particular. 
Table 5 Cause of stillbirth and condition of mother for small-for-gestational age babies, $n=1227$

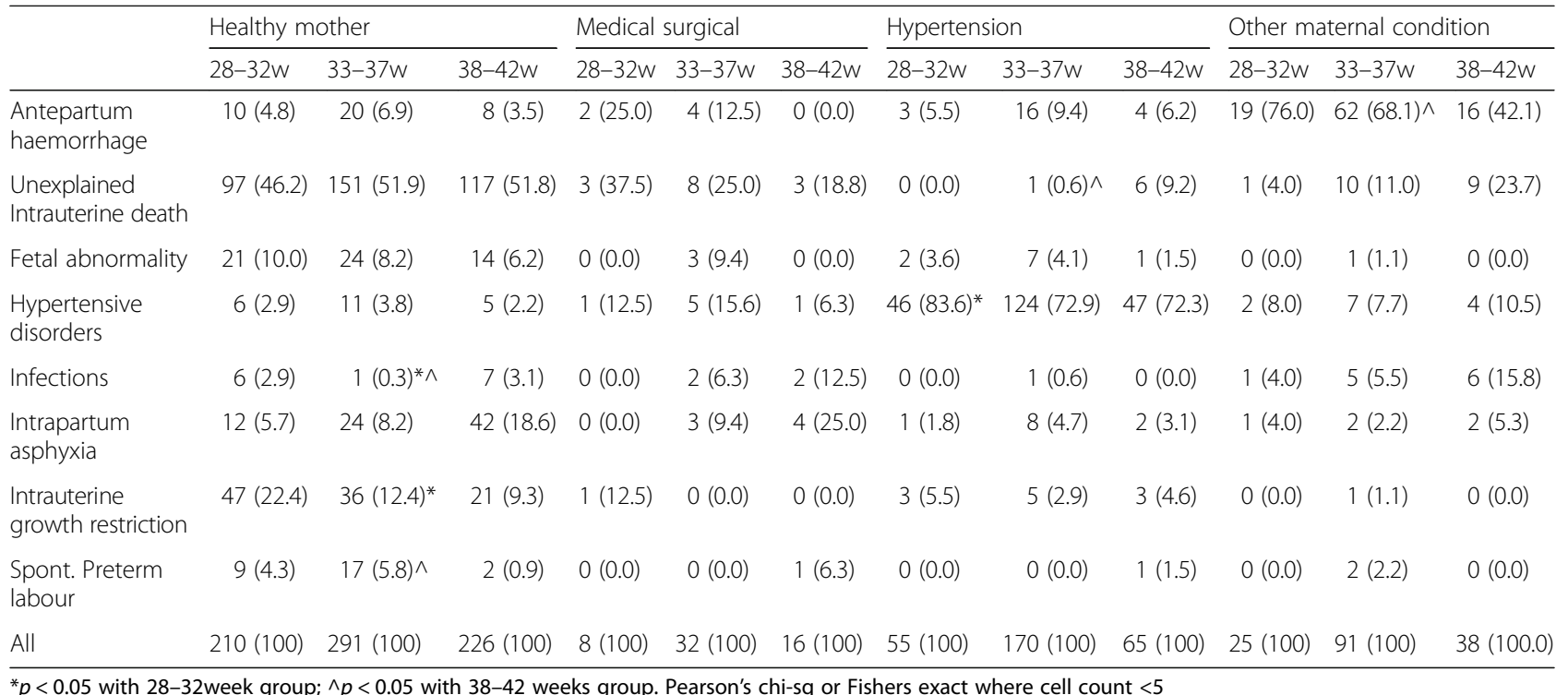

Current antenatal care timing differs between the provinces, with Western Cape, the most well-resourced province, continuing fortnightly antenatal care visits between 32 and 38 weeks, while Limpopo and Mpumalanga cease antenatal care visits between 32 and 38 weeks. Previous work has shown that stillbirth risk is increased during periods without antenatal care [12]. The peak in stillbirths for SGA babies seen in all provinces between 33 and 37 weeks gestation suggests that the current detection and management of SGA is not adequate even in Western Cape where frequent antenatal care visits occur.

\section{Causes of death/mother's condition}

Growth restriction may not necessarily play a principle role in the cause of death for all SGA babies, as SGA may also be due to slow growth of an otherwise healthy baby $[4,13]$. In our study a greater proportion of SGA babies had deaths due to hypertension which is known to have placental pathology [13], indicating that growth restriction played a role in these deaths. It is important to consider that all the babies in the current cohort were considered viable (i.e. $>1000 \mathrm{~g}$ and $>28$ weeks) and that very severe cases of placental insufficiency and congenital abnormalities could have died as late miscarriages.

Table 6 Cause of Early neonatal death and condition of mother for small-for-gestational age babies, $n=388$

\begin{tabular}{|c|c|c|c|c|c|c|c|c|c|c|c|c|}
\hline & \multicolumn{3}{|c|}{ Healthy mother } & \multicolumn{3}{|c|}{ Medical surgical } & \multicolumn{3}{|c|}{ Hypertension } & \multicolumn{3}{|c|}{ Other maternal condition } \\
\hline & $28-32 w$ & $33-37 w$ & $38-42 w$ & $28-32 w$ & $33-37 w$ & $38-42 w$ & $28-32 w$ & $33-37 w$ & $38-42 w$ & $28-32 w$ & $33-37 w$ & $38-42 w$ \\
\hline $\mathrm{APH}$ & $1(1.9)$ & $3(2.5)$ & $3(2.9)$ & $0(0.0)$ & $0(0.0)$ & $0(0.0)$ & $0(0.0)$ & $1(2.9)$ & $0(0.0)$ & $8(50.0)$ & $1(8.3)^{*}$ & $2(25.0)$ \\
\hline $\begin{array}{l}\text { Unexplained } \\
\text { Intrauterine } \\
\text { death }\end{array}$ & $0(0.0)$ & $1(0.8)$ & $0(0.0)$ & $0(0.0)$ & $0(0.0)$ & $0(0.0)$ & $0(0.0)$ & $0(0.0)$ & $0(0.0)$ & $0(0.0)$ & $0(0.0)$ & $0(0.0)$ \\
\hline $\begin{array}{l}\text { Fetal } \\
\text { abnormality }\end{array}$ & $6(11.5)$ & $19(16.1)$ & $24(23.1)$ & $0(0.0)$ & $0(0.0)$ & $3(50.0)$ & $1(5.6)$ & $4(11.4)$ & $2(13.3)$ & $0(0.0)$ & $1(8.3)$ & $1(12.5)$ \\
\hline $\begin{array}{l}\text { Hypertensive } \\
\text { disorders }\end{array}$ & $1(1.9)$ & $9(7.6) \wedge$ & $1(1.0)$ & $0(0.0)$ & $0(0.0)$ & $1(16.7)$ & $16(88.9)$ & $21(60.0)$ & $5(33.3)$ & $0(0.0)$ & $1(8.3)$ & $0(0.0)$ \\
\hline Infections & $0(0.0)$ & $3(2.5)$ & $3(2.9)$ & $0(0.0)$ & $0(0.0)$ & $1(16.7)$ & $0(0.0)$ & $0(0.0)$ & $0(0.0)$ & $1(6.2)$ & $2(16.7)$ & $2(25.0)$ \\
\hline $\begin{array}{l}\text { Intrapartum } \\
\text { asphyxia }\end{array}$ & $2(3.8)$ & $24(20.3)^{*}$ & $58(55.8)$ & $0(0.0)$ & $1(33.3)$ & $1(16.7)$ & $0(0.0)$ & $4(11.4) \wedge$ & 7 (46.7) & $0(0.0)$ & $2(16.7)$ & $3(37.5)$ \\
\hline $\begin{array}{l}\text { Intrauterine } \\
\text { growth } \\
\text { restriction }\end{array}$ & $1(1.9)$ & $7(5.9)$ & $8(7.7)$ & $0(0.0)$ & $0(0.0)$ & $0(0.0)$ & $1(5.6)$ & $2(5.7)$ & $1(6.7)$ & $0(0.0)$ & $1(8.3)$ & $0(0.0)$ \\
\hline $\begin{array}{l}\text { Spont. Preterm } \\
\text { labour }\end{array}$ & $41(78.8)$ & $52(44.1)$ & $7(6.7)$ & $1(100.0)$ & $2(66.7)$ & $0(0.0)$ & $0(0.0)$ & $3(8.6)$ & $0(0.0)$ & 7 (43.8) & $4(33.3)$ & $0(0.0)$ \\
\hline All & $52(100.0)$ & 118 (100.0) & $104(100.0)$ & $1(100.0)$ & $3(100.0)$ & $6(100.0)$ & $18(100.0)$ & $35(100.0)$ & $15(100.0)$ & $16(100.0)$ & $12(100.0)$ & $8(100.0)$ \\
\hline
\end{tabular}


Therefore the deaths in the current study could have been potentially avoided if at risk fetuses were detected early.

Detecting SGA is complicated as in most cases the mother is healthy. In the current study there was no increase in poor maternal condition for SGA babies and more than half of all deaths had a healthy mother. Of mothers that were healthy the greatest proportion of SGA stillbirths were due to unexplained intrauterine death. Earlier detection of fetuses at risk antenatally may reduce the number of unexplained intrauterine deaths.

\section{Challenges with detection}

Better detection of SGA babies is needed in South Africa and LMICs. Palpation and symphysis fundal height are commonly used in LMICs due to limited alternative resources, despite the limited evidence to support this as an effective method to predict growth restriction [14]. Clinical trials in high-income countries estimate that up to $76 \%$ of SGA cases can be detected antenatally [15]. The use of Doppler velocimetry to measure altered umbilical artery blood flow in high risk women has enhanced the ability to detect fetuses with pathological growth restriction [16], reducing perinatal mortality [17]. However, challenges with Doppler measurement in South Africa are present as there are a large number of perinatal deaths to low-risk healthy mothers [7] and who would therefore not be referred for screening. Studies in South Africa have explored the use of a continuous wave Doppler analyser using a PC (Umbiflow), a simpler alternative to umbilical artery Doppler, which can be operated by nurses and midwives at the primary health care centre level $[18,19]$. The Umbiflow is able to detect fetuses at risk of stillbirth based on abnormal umbilical artery blood flow. While meta-analyses in high-income countries found Doppler use in low-risk pregnancies to be ineffective to reduce perinatal mortality and morbidity [20], there may be potential benefit of Doppler or Umbiflow use in low risk populations in LMICs where stillbirth rates are higher. However, once a fetus at risk of stillbirth is detected, quality clinical care must also be provided to increase the risk of survival.

\section{Challenges with clinical management}

Once SGA has been detected there are challenges in the clinical management of such babies. Currently there are no effective approaches for the reversal or improvement of the growth pattern of a fetus [21], therefore prenatal clinical management is focused on identifying the optimal timing of delivery. The gestational age of the fetus is a critical component of the decision-making process, as fetal mortality is lower than neonatal mortality prior to 31 weeks [22], and delivery after 39 weeks results in increased perinatal mortality [23]. While it is known that the neonatal mortality risk is higher for preterm SGA babies compared to term SGA babies [1], it unclear how much size-for-gestational age impacts the risk of neonatal mortality in the preterm compared to late preterm infant $[24,25]$. It has recently been suggested that the delivery of SGA babies around 37 weeks is optimal to avoid increased risk of stillbirth occurring after week 37 [26]. Causes of death for SGA babies in other studies have shown different patterns across gestation with a greater proportion of deaths due to congenital abnormality (32-42 weeks) and intrapartum asphyxia (37-42 weeks) at older gestations [5]. We observed similar findings in our data with SGA deaths from intrapartum asphyxia and fetal abnormality occurring more frequently at older gestations. Standard guidelines for managing labour in South African include partogram and monitoring of fetal heart rate with a fetal stethoscope or doptone in Community Health Centres and electronically at district hospitals and above. However it is estimated that in $44 \%$ of deaths these guidelines are not adhered to due to limited resources and staff [27]. Caesarean delivery is not readily accessible in some districts, and long transport times exist between Community Health Centres to facilities that are able to perform caesarean section deliveries. It is likely these factors play a role in the high proportion of deaths due to fetal asphyxia observed in the current study. It is also important to note that spontaneous preterm labour is an underlying cause of early neonatal death where the maternal condition contributes to increased risk of death from disorders associated with prematurity. Early neonatal deaths for preterm neonates reflect access and quality of care after birth for preterm infants. The final cause of death for a preterm neonate could be due to a causes such as hyaline membrane disease, hypoxic ischaemic encephalopathy and meconium aspiration. Doppler measurements in combination with growth charts can be used to inform the management of SGA pregnancies [17]. This has been shown to decrease the induction of labour and hospital admissions in high-income countries [17].

\section{Limitations}

There are some limitations to the current study. First, there is likely some ambiguity in the assignment of gestational age from the perinatal audit data. Last menstrual period or ultrasound estimates for gestational age may not be accurate and the SGA category may erroneously capture appropriately sized infants who measure small for their misassigned gestational age. We sought to reduce this issue by using only data where gestational age estimates were considered 'certain'. Second, macerated SGA babies are likely to be overestimated as death may have occurred up to 2 weeks prior [28] thus the fetus may 
have been appropriate-for-gestational age at the time of death. Third, as we had access to aggregated data at a centre level, and data for the number of live births for SGA, AGA and LGA were unavailable we were unable to calculate stillbirth risk, relative risks between live and stillborn babies or perform individual unit analysis using multivariable regression. Fourth, both multiple and single gestations were included in the current study. These were not separated due to limited statistical power and therefore any differences in patterns of mortality between multiple and single gestations are not presented in the current study. Deaths directly related to multiple gestation such as twin-to-twin transfusion only represented $0.3 \%$ of all deaths in the current study, therefore it is unlikely that the inclusion of multiple gestations introduced significant bias.

\section{Conclusion}

Mortality from SGA in South Africa accounts for a considerable number of deaths, yet there is little research on the timing, causes and detection of SGA in low-resource settings. The detection and management of SGA is important as most deaths occur in late preterm or term infants, where the chance of survival is high when adequate care can be delivered. If SGA infants can be detected antenatally and managed effectively there is an opportunity to significantly reduce the burden of perinatal mortality in LMICs. Further studies on the relationship between antenatal detection and outcome of SGA are needed, especially in LMICs.

\section{Abbreviations}

AGA: Appropriate-for-gestational-age; END: Early neonatal death (up to 7 days neonatal life); IUGR: Intrauterine growth restriction; LGA Large-for-gestational-age; LMIC: Low-and-middle-income-countries; PPIP: Perinatal Problems Identification Program; SGA: Small-for-gestational-age

\section{Acknowledgments}

We are grateful for the funding provided through the University of Western Australia Research Collaboration Award to the support this research.

\section{Funding}

University of Western Australia, Research Collaboration Award.

\section{Availability of data and materials}

The data that support the findings of this study are available from Perinatal Problem Identification Program but restrictions apply to the availability of these data, which were used under license for the current study, and so are not publicly available. Data are however available from the authors upon reasonable request and with permission of [Perinatal Problem Identification Program].

\section{Authors' contributions}

$\mathrm{TL}$ and RP conceptualized the manuscript. TL performed data analysis; $T L, D P$ and RP interpreted findings, TL drafted manuscript. DP and RP reviewed the manuscript and approved the final version. All authors read and approved the final manuscript.

\section{Competing interests}

The authors declare they have no competing interests.
Consent for publication

Not applicable.

\section{Ethics approval and consent to participate}

The PPIP program has ethical approval from the University of Pretoria. The data is collected with permission from the South African Department of Health. This secondary analysis was approved by the PPIP technical task team and UWA Human Ethics Committee.

\section{Author details}

${ }^{1}$ Centre for Health Services Research, School of Population Health, The University of Western Australia (M431), 35 Stirling Highway, Crawley, WA 6009, Australia. ${ }^{2}$ SAMRC Maternal and Infant Health Care Strategies, Department of Obstetrics and Gynaecology, University of Pretoria, Pretoria, South Africa.

Received: 1 August 2016 Accepted: 18 October 2016

Published online: 21 October 2016

\section{References}

1. Katz J, Lee AC, Kozuki N, Lawn JE, Cousens S, Blencowe H, Ezzati M, Bhutta ZA, Marchant T, Willey BA, et al. Mortality risk in preterm and small-for-gestational-age infants in low-income and middle-income countries: a pooled country analysis. Lancet. 2013;382(9890):417-25.

2. Chiswick ML. Intrauterine growth-retardation. Brit Med J. 1985;291 (6499):845-8.

3. Pilliod RA, Cheng YW, Snowden JM, Doss AE, Caughey AB. The risk of intrauterine fetal death in the small-for-gestational-age fetus. Am J Obstet Gynecol. 2012;207(4):318.e1-6.

4. Gardosi J, Mul T, Mongelli M, Fagan D. Analysis of birthweight and gestational age in antepartum stillbirths. Br J Obstet Gynaecol. 1998;105(5):524-30.

5. Decourcywheeler RHB, Wolfe CDA, Warburton F, Goodman J, Reynolds F, Gamsu H. The association between small-size for gestational-age and perinatal and neonatal death in a UK-regional-health-authority. Paediatr Perinat Ep. 1995;9(4):431-40.

6. Williams RL, Creasy RK, Cunningham GC, Hawes WE, Norris FD, Tashiro M. Fetal growth and perinatal viability in California. Obstet Gynecol. 1982;59(5):624-32.

7. Allanson ER, Muller M, Pattinson RC. Causes of perinatal mortality and associated maternal complications in a South African province: challenges in predicting poor outcomes. BMC Pregnancy and Childbirth. 2015:15:37.

8. Velaphi SC, Mokhachane M, Mphahlele RM, Beckh-Arnold E, Kuwanda ML, Cooper PA. Survival of very-low-birth-weight infants according to birth weight and gestational age in a public hospital. S Afr Med J. 2005; 95(7):504-9

9. Allanson ER, Pattinson RC. Quality-of-care audit and perinatal mortality in South Africa. B World Health Organ. 2015;93:424-8.

10. Theron GB, Geerts L, Thompson ML, Theron AM. A centile chart for fetal weight for gestational ages 24-27 weeks. S Afr Med J. 2008;98(4):270-1.

11. Theron GB, Thompson ML. A centile chart for birth weight for an urban population of the Western Cape. S Afr Med J. 1995;85(12):1289-92.

12. Vogel JP, Habib NA, Souza JP, Gulmezoglu AM, Dowswell T, Carroli G, Baageel HS, Lumbiganon P, Piaggio G, Oladapo OT. Antenatal care packages with reduced visits and perinatal mortality: a secondary analysis of the WHO Antenatal Care Trial. Reprod Health. 2013;10:19.

13 Gruenwald P. Chronic fetal distress and placental insufficiency. Biol Neonatorum. 1963;5(3-4):215

14 Peter JR, Ho JJ, Valliapan J, Sivasangari S. Symphysial fundal height (SFH) measurement in pregnancy for detecting abnormal fetal growth. Bjog-Int J Obstet Gy. 2012;119:78.

15 Pearce JM, Campbell S. A comparison of symphysis-fundal height and ultrasound as screening-tests for light-for-gestational age infants. Brit J Obstet Gynaec. 1987;94(2):100-4.

16 Reuwer PJ, Bruinse HW, Stoutenbeek P, Haspels AA. Doppler assessment of the fetoplacental circulation in normal and growth-retarded fetuses. Eur J Obstet Gynecol Reprod Biol. 1984;18(4):199-205.

17 Neilson JP. Alfirevic Z. Doppler ultrasound for fetal assessment in high risk pregnancies. Cochrane Database Syst Rev. 2000;2:CD000073. 
18 Hugo EJC, Odendaal HJ, Grove D. Evaluation of the use of umbilical artery Doppler flow studies and outcome of pregnancies at a secondary hospital. J Matern-Fetal Neo M. 2007;20(3):233-9.

19 Theron GB, Theron AM, Odendaal HJ, Bunn AE. Comparison between a newly developed PC-based Doppler umbilical artery waveform analyser and a commercial unit. Samj S Afr Med J. 2005;95(1):62-4.

20 Alfirevic Z, Stampalija T, Medley N. Fetal and umbilical Doppler ultrasound in normal pregnancy. Cochrane Database Syst Rev. 2015;4:CD001450.

21 Gulmezoglu M, de Onis M, Villar J. Effectiveness of interventions to prevent or treat impaired fetal growth. Obstet Gynecol Surv. 1997;52(2):139-49.

22 Seeds JW, Peng T. Impaired growth and risk of fetal death: is the tenth percentile the appropriate standard? Am J Obstet Gynecol. 1998;178(4): 658-69.

23 Mandujano A, Waters TP, Myers SA. The risk of fetal death: current concepts of best gestational age for delivery. Am J Obstet Gynecol. 2013;208(3):207 e201-208.

24 Pulver LS, Guest-Warnick G, Stoddard GJ, Byington CL, Young PC. Weight for gestational age affects the mortality of late preterm infants. Pediatrics. 2009;123(6):E1072-7.

25 Gilbert WM, Danielsen B. Pregnancy outcomes associated with intrauterine growth restriction. Am J Obstet Gynecol. 2003;188(6):1596-9.

26 Trudell AS, Cahill AG, Tuuli MG, Macones GA, Odibo AO. Risk of stillbirth after 37 weeks in pregnancies complicated by small-for-gestational-age fetuses. Am J Obstet Gynecol. 2013;208(5):376 e371-377.

27 Pattinson RC. Saving babies 2010-2011: eighth report on perinatal care in south Africa. In: Pretoria. 2013. p. 18

28 Genest DR, Singer DB. Estimating the time of death in stillborn fetuses: III. External fetal examination; a study of 86 stillborns. Obstet Gynecol. 1992;80(4):593-600.

\section{Submit your next manuscript to BioMed Central and we will help you at every step:}

- We accept pre-submission inquiries

- Our selector tool helps you to find the most relevant journal

- We provide round the clock customer support

- Convenient online submission

- Thorough peer review

- Inclusion in PubMed and all major indexing services

- Maximum visibility for your research

Submit your manuscript at www.biomedcentral.com/submit 